\title{
La jurisdicción inquisitorial y la eclesiástica en la historiografía
}

\author{
Roberto López VeLA *
}

La elección del tema no es gratuita. En un curso de la Universidad Menéndez Pelayo sobre Inquisición y Censura en julio de $1982^{1}$, tuve la ocasión de escuchar una brillante conferencia de M. Avilés sobre la historiografía inquisitorial en el siglo pasado. Fue mi primer acercamiento a un tema tan apasionante como olvidado. Desde entonces me quedó la preocupación por abordar un estudio de la abundante historiografía inquisitorial. Una cuestión que poco a poco me gustaría realizar. Este es mi homenaje a quienes fueron mis iniciadores en los estudios sobre la Inquisición, además de amigos.

Al poco de comenzar mis estudios en la U. Autónoma de Madrid conocí a M. Avilés, que por entonces, durante algunos meses daba clases de Historia Antigua. Cosas de la Universidad de aquellos años. Lo cierto es que nunca me dio clases de Historia Moderna, pero las circunstancias y sus generosos ofrecimientos para trabajar sobre la burocracia inquisitorial hicieron que al final acabase en esta especialidad. Pronto entré a formar parte del grupo que por entonces se estaba formando en el Departamento de Historia Moderna de la Universidad Autónoma para investigar en diferentes facetas de la actividad del Tribunal ${ }^{2}$. Desde entonces mantuve una sincera amistad con Miguel y María. El fue quien me introdujo en los

\footnotetext{
* Universidad de Cantabria

1 Esta conferencia la pronunció en el curso organizado por J. A. Escudero «nquisición y censura en la España moderna" celebrado en julio de 1982. Años más tarde la publicó con considerables cambios bajo el título «La literatura inquisitorial. (Aportaciones a la historia de un género historiográfico)", Espacio, Tiempo y Forma, $n^{\circ} 4$ (1989).

2 M. Avilés proporciona algunas noticias sobre los orígenes de este grupo en "Investigaciones sobre la Historia de la legislación inquisitorial», en Perfiles jurídicos de la Inquisición. Madrid, (Ed). Escudero, J. A., 1989, págs. 111-120. También vid. Ocaña Torres, M. L., «EI Corpus jurídico de la Inquisición Española», en La Inquisición española. Nueva visión: nuevos horizontes. Madrid, Pérez Villanueva, (Ed) 1980, págs. 913-916.
} 
estudios inquisitoriales y fue mi primer maestro en estas lides. Sin embargo, tan sólo actuó como director de mi tesina durante algunos meses, lo cual no impidió que me prestase generosamente su colaboración y ayuda en distintos momentos. Una huella positiva que siempre recordaré.

\section{A. ALGUNAS CARACTERISTIICAS DE LA HISTORIOGRAFIA INQUISITORIAL}

La existencia de una ingente cantidad de títulos dedicados a la Inquisición no es índice de un conocimiento suficiente sobre las distintas facetas de la actividad del Tribunal. Para entender este magma de obras, hay que tener muy presente las peculiaridades de la bibliografía inquisitorial. En ella se pueden encontrar silencios sorprendentes durante períodos prolongados en aspectos importantes. Puede haber, incluso, cuestiones no planteadas con anterioridad. Pero esto no es tan frecuente en una bibliografía con tantos años a su espalda y que siempre se ha distinguido por estar implicada a fondo en todo tipo de polémicas políticas e intelectuales. Sólo cuando se trata de terrenos historiográficamente «nuevos», se puede considerar que, quizá, los estudiosos del Santo Oficio se han ocupado poco de la perspectiva en cuestión o lo han hecho de forma tangencial. En la bibliografía inquisitorial no son tantos los terrenos verdaderamente vírgenes. Mejor o peor, con más o menos profundidad o precisión, son numerosos los autores que se han ocupado de casi todos los aspectos centrales que pueden preocupar a los estudiosos del Santo Oficio.

El hecho de que una cuestión no cuente con análisis minuciosos, no debe llamar a engaño. Esto sucede a menudo y no por ello se debe pensar que los distintos autores no se han preocupado de teorizar al respecto. Gran parte de la bibliografía inquisitorial se ha construido fuera de las preocupaciones estrictamente historiográficas y muchas veces con un conocimiento limitado de las fuentes. Sin embargo, sí ha realizado interpretaciones globales en las que cada parte, por escaso que sea su tratamiento, tiene sentido en función del todo. Es decir, hay pocos análisis monográficos, pero muchas interpretaciones que han ejercido una influencia decisiva en la renovación de los estudios inquisitoriales desde mediados de la década de 1970. Por tanto, se trata de un legado complejo, lleno de sugerencias, tópicos y análisis olvidados.

Se podría considerar que el nacimiento de la bibliografía sobre el Santo Oficio se remonta a las primeras décadas del siglo xIX. Esta afirmación, en si misma, puede ser bastante discutible, porque sobre el Tribunal se escribió también antes y mucho. No obstante, creo que a la hora de 
intentar hacer un análisis historiográfico sobre esta producción las obras de Puiblanch o Llorente marcan un hito. Por primera vez se pretende hacer una historia del Santo Oficio con ciertos criterios de erudición y no simples panfletos. Partiendo de estas fechas, no es exagerado decir que en la bibliografía inquisitorial se puede encontrar de todo, en las más diversas calidades y escrita con objetivos bien diferenciados ${ }^{3}$.

De entre su gran variedad hay una cuestión que merece ser destacada, porque constituye una de sus señas de identidad, quizá la más significativa: Sus autores han estado comprometidos con su realidad política. Para muchos el Santo Oficio ha sido una fácil cantera de terrores y obscurantismos para sacar argumentos propagandísticos en contra de las corrientes conservadoras. Para otros, en cambio, su existencia impidió que las guerras civiles desgarrasen «España». Con ello suministraban una justificación ideológica a las soluciones políticamente más autoritarias. Esto, generalmente, implicaba una selección de cuestiones y una forma de tratarlas que dependía más de la situación política en que escribiese cada autor, que de la importancia que hubiese tenido tal o cual aspecto en la trayectoria histórica del Santo Oficio. Por ello, no conviene caer en la trampa de pensar en una evolución lineal de la historiografía inquisitorial hacia mayores niveles de calidad y riqueza de problemas planteados. En muchos aspectos, especialmente en lo referente al tratamiento de las cuestiones políticas, el camino ha sido exactamente el inverso.

Dentro de los aspectos que han tenido una evolución historiográfica sorprendente, destaca el tratamiento de las dos jurisdicciones eclesiásticas más poderosas del Antiguo Régimen: La ordinaria y la inquisitorial. Una cuestión que fue motivo de permanente debate entre los que a comienzos del siglo XIX pretendían la eliminación o la continuidad del Santo Oficio. Lógicamente este problema se encuentra muy presente en la producción de lo que podríamos denominar los primeros historiadores del tribunal. Sin embargo, su eco progresivamente se fue apagando hasta prácticamente desaparecer. A medida que los conflictos entre el naciente Estado burgués español y la Iglesia se iban delimitando políticamente, también dejaba de interesar a quienes escribían sobre el Tribunal las conflictivas relaciones entre los inquisidores y «los obispos». Por tanto, no es extraño que para la historiografía más reciente esta vieja cuestión aparezca como algo novedoso, aunque, sin embargo, tienda a moverse en

3 M. Avilés hace un esfuerzo por periodizar la trayectoria de la producción del "género" historiográfico inquisitorial, vid. «La literatura Inquisitorial. (Aportaciones a la historia de un género historiográfico)», op. cit., págs. 82-89. 
el marco de los problemas planteados hace tantos años. Y es que la forma de avanzar historiográficamente no es relegar lo escrito con anterioridad, sino hacer una crítica en profundidad de sus logros y sus deficiencias, despejando el camino para futuros trabajos.

Las críticas de los diputados de las Cortes de Cádiz a la Inquisición no fueron muy originales. Entre ellas se pudo escuchar un argumento largamente repetido por cuantos se habían opuesto al Tribunal y que había sido especialmente utilizado por los llustrados. Para los diputados hay que restituir «la ley de Partida», según la cual la jurisdicción sobre las cuestiones de fe corresponde a los obispos ${ }^{4}$. Entre los que pretendían la abolición del Tribunal en las primeras décadas del siglo XIX, se consideraba al Santo Oficio como una institución que había usurpado la jurisdicción de los obispos para corregir y castigar a los herejes. Pero también denunciaban los privilegios que se arrogaban los miembros de la Inquisición amparando con supuestas delegaciones "apostólicas» todas sus arbitrariedades y abusos. Esta cuestión merecía la mayor atención a estos autores, hasta convertirse en uno de los ejes más destacados de su combate contra la Inquisición. En efecto, entonces existía una considerable minoría entre el clero secular urbano y sectores intelectuales de la Iglesia, que pretendía una reforma en profundidad de ésta para situarla en la verdadera dimensión pastoral que la correspondía, adecuándola a la nueva «filosofía». El posicionamiento frontal del grueso de la Iglesia contra el liberalismo y la laminación de estos sectores reformadores en el seno de ésta, constituye una consecuencia, entre otros factores, de las Cortes de Cádiz. En ellas, la Iglesia tomó conciencia de los peligros que encerraban los intentos de los «liberales» para sus privilegios, así como los esfuerzos que desplegaba para recortar en profundidad su patrimonio y poder. Los «liberales» era la versión nacional de la «impía» Revolución Francesa ${ }^{5}$.

Los críticos del Tribunal en esta época consideraban que a través de estos excesos los tribunales inquisitoriales consiguieron establecer una relación particular con los cuerpos burocráticos eclesiásticos y seculares. No es extraño que el comportamiento de los servidores inquisitoriales se convirtiese en un baremo sobre la bondad o maldad intrínseca de la organización. Los detractores del Santo Oficio tendían a valorar a los inquisidores y sus subordinados como un cúmulo de maldades y ambicio-

Martí Gilabert, F., La abolición de la Inquisición en España. Pamplona 1975, págs. 114115.

Callahan, W., Iglesia, poder y sociedad en España, 1750-1874.Madrid 1989. Cuenca ToRIBIO, J. M., La iglesia española ante la revolución liberal. Madrid 1971. 
nes, mientras los defensores de la organización les presentaban como la parte más culta y recta del clero hispano. Era una perspectiva teñida de juicios morales por ambas partes, pero a través de ella estaban intentando analizar las relaciones de la Inquisición con la sociedad. En esta confrontación tenían un papel importante como prueba las cuestiones derivadas del fuero de los miembros del Tribunal y los múltiples problemas que generaron.

En el siglo XIX, especialmente en sus primeras décadas, los documentos más significativos del conflicto entre Inquisición y otros cuerpos burocráticos eran fácilmente accesibles y perfectamente conocidos. Esto permitió a los autores de estos años plantearse la cuestión con cierto conocimiento. La iniciativa indiscutible en la bibliografía inquisitorial del siglo pasado y principios de éste, correspondió sin género de dudas a los detractores del Santo Oficio. Ellos también serán los que más se preocupen de referirse a los privilegios de los servidores del Tribunal. Era un terrenos propicio en el que demostrar «los abusos» de los miembros del Santo Oficio y sus esfuerzos para avasallar y subordinar a las personas y a otras instituciones. Se movían dentro de una perspectiva más moral que política, social o jurídica. En este sentido, las acusaciones de las Cortes o bien del Consejo de Castilla, Juntas, etc. constituyeron la base documental desde la que ofrecer una panorámica de la oposición al Santo Oficio. En el caso de las Cortes eran las expresiones del malestar o la protesta de la población contra el Tribunal, elevadas al rey por sus representantes ${ }^{6}$. Una interpretación notablemente distorsionada, que en sí misma constituía un «abuso». Ni a los procuradores de las Cortes se les puede calificar de representantes de la soberanía del pueblo ${ }^{7}$, ni pretendían la abolición radical de la Inquisición. Ésta es una perspectiva propia de los liberales del XIX y su visión constitucionalista proyectada hacia el pasado.

- Seguramente, el primero que desarrolló esta interpretación sistemáticamente es PulGBLANCH, A., La Inquísición sin máscara, cuya primera edición data de 1811 (edición facsímil. Barcelona 1988). A pesar de ser hoy un autor bastante olvidado por la historiografía del Tribunal fue, sin embargo, uno de los que ejerció más poderosa influencia en el siglo xix, especialmente en sus primeras décadas. "Queda probado, afirma Puigblanch, que a la inquisición considerada según su espíritu y sistema le convienen exactamente las calidades del tirano; es ya tiempo de que indaguemos si sus procedimientos desmienten o si confirman más bien este carácter. Ninguna cosa decidirá mejor la questión que las repetidas quexas, que contra ella ha elevado a la superioridad, toda clase de personas y cosporaciones», Ibidem, pág. 362.

7 Para un repaso de la antigua bibliografía sobre las Cortes vid. el prólogo de VALDEÓN Baruque, J., PIskorski, W., Las Cortes de Castilla en el período de tránsito de la Edad Media a la Edad Moderna, 1188-1520. Barcelona 1977; vid. también la introducción a su libro de FORTEA PÉrez, J. I., Monarquia y Cortes en la Corona de Castilla. Las ciudades ante la politica fiscal de Felipe II. Cortes de Castilla y León 1990. 
Ciertamente, se criticó el modelo de organización, pero los liberales olvidaban añadir algo importante: no se discutieron las tareas represivas de la Inquisición en los terrenos de la fe. Lo que las Cortes, o los Consejos pedían es que la Inquisición española se acercase al modelo de los que fueron las inquisiciones medievales en cuanto al número y estructura de su organización, dedicándose exclusivamente a las causas de la fe ${ }^{8}$. Éste es un aspecto que conviene precisar antes de entrar en materia para evitar malentendidos. En todas las crisis que se produjeron en el siglo XVI y XVII ningún reino u órgano representativo o de gobierno de estos, se planteó acabar con la Inquisición en cuanto organización encargada del control ideológico y la represión de los disidentes. Para encontrar un rechazo generalizado a las tareas intrínsicamente inquisitoriales entre amplios sectores de las élites de gobierno y de las bases sociales de la Monarquía, habrá que esperar a la última mitad del siglo XVIII ${ }^{9}$. En los siglos XVI y XVII lo que sí se discutió, y mucho, fue el grado de poder que debía concentrar la Inquisición en la Monarquía Católica o su lugar en la sociedad estamental.

\section{B. LOS COMIENZOS DE LA HISTORIOGRAFÍA}

La calidad de los análisis realizados por los autores del siglo XIX es muy desigual y, por lo general, suelen adolecer de poco originales. El gran aporte informativo llegará a principios del siglo de la mano de Puigblanch y Llorente. El tratamiento de las cuestiones derivadas del fuero en estos dos autores es de una gran calidad, sólo superada por Lea un siglo después desde una perspectiva más positivista y con una interpretación más sistemática y exhaustiva. Tanto Puigblanch como Llorente se alinearon con los sectores «liberales» que pretendían la abolición de la Inquisición y la reforma en profundidad de la Iglesia. Llorente participó en el gobierno de José Bonaparte. Puigblanch escribió su obra destinada a alimentar las corrientes que en Cádiz pugnaban por la abolición de la Inquisición.

Puigblanch, que publica la primera edición de su obra en 1811, realiza una crítica implacable contra los «abusos» inquisitoriales. En ella hace gala de un conocimiento nada despreciable sobre los conflictos de la

\footnotetext{
8 López VELA, R., "Estructura y funcionamiento de la burocracia inquisitorial (1643-1667)", en Inquisición española. Nuevas aproximaciones. Madrid 1987, pág. 213.

9 JimÉnEZ MONTESERÍn, M., "La abolición del Tribunal (1808-1834)", en Historia de la Inquisición en España y América. Madrid 1984, pág. 1424.
} 
Inquisición. Algo muy destacable teniendo en cuenta que no tenía acceso a los archivos inquisitoriales ${ }^{10}$. No es de extrañar que su documentación no sea de primera mano y presente grandes lagunas. No obstante, su aportación es interesante por las agudas valoraciones que realiza sobre los mecanismos que utilizó el Santo Oficio para vencer en la dinámica de conflicto en que vivió permanentemente. Quizá, sin embargo, lo más valioso está en la estupenda documentación que da a conocer, singularmente destacable en lo referente a las tensiones entre el Santo Oficio con los «obispos», a los que dedica una gran atención. Sin duda, entre los clásicos es el autor que, comparativamente, dedica más atención a este aspecto.

Conviene matizar, no obstante, lo que Puigblanch, al igual que ocurre con Llorente o con los autores del siglo XIX, entienden por «obispos». Estos autores no hacen distinción entre los conflictos de competencia entre los jueces ordinarios con los inquisidores, derivados de pleitos civiles o criminales de sus servidores, de los que inicia un obispo o el cabildo eclesiástico por problemas de comparecencia en actos públicos, lectura de edictos de fe... Bajo el concepto de «obispos" incluyen todo lo que concierne a la jurisdicción en cuyo vértice se sitúa el obispo. Puigblanch, como gran parte de los críticos del Santo Oficio en el siglo XIX, consideraba que la Inquisición se oponía a las enseñanzas del cristianismo y había usurpado las funciones de los obispos, convirtiéndose en una organización que obstaculizaba notablemente la labor de éstos en cuanto pastores de la comunidad cristiana. Coherente con este planteamiento dedica gran atención a los argumentos de los «obispos». No se puede olvidar que la publicación de su obra se inscribe en la preparación del arduo debate que se sostendrá poco después en las Cortes de Cádiz para tratar la abolición del Tribunal ${ }^{11}$, postura con la que Puigblanch estaba profundamente comprometido ${ }^{12}$.

De su obra se desprende una constante oposición global por parte de los representantes políticos de los reinos hispánicos a la actitud de pre-

10 Puigblanch, A., La Inquisición sin máscara. Barcelona 1988, págs. 370-447. Su información está sacada de una lectura atenta de ciertas consultas elevadas al rey por el Consejo de Castilla en la época de Carlos III, en las que se resume el contenido de otras consultas del siglo XVII. Sin duda, estas representaciones, además de estar en los archivos de este organismo, habían alcanzado gran difusión a finales del siglo xvill. También alude a algunos informes o memoriales publicados en la última mitad del siglo XVIII.

11 Martí Gilabert, F., La abolición de la Inquisición, op. cit.; Pérez-VILARIÑo, J., Inquisición y constitución en España. Madrid 1973.

12 Avilés FernándeZ, M., «La literatura inquisitorial. (Aportaciones a la historia de un género historiográfico)», op. cit, pág. 79ss. 
potencia de la Inquisición y su intento de alcanzar la supremacía sobre el resto de las jurisdicciones en cuestiones que nada tenían que ver con la fe. Puigblanch no parte de un análisis de los privilegios concretos que concedió el papado o la Monarquía al Santo Oficio, los mecanismos jurídicos con que se debía utilizar, los medios de composición, etc. Para él la Inquisición tiene una fundación viciada, por cuanto desliga la función pastoral de la reprensión de aquellos que confunden el mensaje de Cristo. Una reprensión que, por lo demás, se debía entender más en términos caritativos que estrictamente represivos. Desde la Edad Media, la Inquisición surge como omnímoda máquina represiva de difícil control, con tendencia a la tiranía. Es por esto que todos los poderes tiránicos la sostuvieron, aunque a veces llegase a escapar a su control ${ }^{13}$. Para los inquisidores era normal apoyar las extralimitaciones de sus subordinados. Esto era la consecuencia del «criminal padrinazgo que franqueaba el tribunal a todo malvado que lo solicitaba, revistiéndole de sus privilegios o para explicarle con más propiedad, abrigándole con su capa» ${ }^{14}$. A ello, habría que añadir la avaricia de poder que siempre tuvo la Inquisición y sus servidores, que la condujo a entrometerse en todo tipo de campos para subordinar a sus órdenes a todas las personas y cuerpos.

En estos conflictos de poder, la Monarquía no se atrevió o no quiso seguir las recomendaciones de sus órganos de justicia y gobierno. Éstos de una forma continuada requirieron un recorte de los privilegios concedidos por el rey al Santo Oficio o la prohibición de que éste utilizase las censuras eclesiásticas contra los ministros seculares o eclesiásticos en cuestiones ajenas a la fe. A veces, no obstante, la Corona intentó imponer mecanismos de control a la acción arbitraria de los inquisidores, exigiendo que se le consultase antes de tomar resoluciones drásticas en determinados problemas ${ }^{15}$. Pero no bastaron estas decisiones puntuales. Los inquisidores y oficiales, protegidos o alentados por el Inquisidor General y Consejo, volvían una y otra vez a las andadas sin que el rey cortase sus desmanes de una forma sistemática y contundente.

Cuando Puigblanch analiza las relaciones entre el Santo Oficio y los «obispos» su posición es muy clara: Nada tiene extraño que los inquisidores se aprovechasen de la jurisdicción concedida por el rey y por el papa para extorsionar a las «autoridades civiles». «Pero que insultase la dignidad de los obispos invadiendo su jurisdicción, y atropellando sus

3 Puigbanch, A., La Inquisición sin máscara, op. cit., pág. 311 ss.

14 Jbidem, pág. 387.

15 Ibidem, pág. 393. 
personas, mientras se preconizaba auxiliador del ministerio pastoral, es un enigma harto difícil de explicar» ${ }^{16}$. En su opinión, esto se debe a que los pontífices en el siglo xiII justificaron la creación de la Inquisición achacando a los prelados negligencia en la persecución de la herejía. Con ello abrieron la puerta a un tribunal que «transtornaba la jerarquía sacerdotal». Según Puiblanch este argumento fue sistemáticamente utilizado por los inquisidores para fundar su prepotencia frente a los ordinarios. Con este principio asentado, el Santo Oficio buscó aumentar su poder en la Iglesia humillando a los ordinarios e intentando someterles a su autoridad. Los inquisidores dieron lugar a conflictos artificiales y entrometiéndose en cuestiones internas de los cabildos eclesiásticos. Unos atropellos que fueron protegidos desde la dirección inquisitorial, en vez de ser reprendidos y controlados. Por esta razón Puiblanch se muestra sorprendido y consternado al comprobar que distintos obispos están dirigiéndose «al Soberano Congreso» (las Cortes de Cádiz) para pedir la restauración del Tribunal, alegando que ellos no pueden desempeñar sus funciones ${ }^{17}$.

Semejante análisis parte de una documentación limitada, aunque selecta. Es la misma documentación que utilizaron o que escribieron quienes pretendieron reformar el Tribunal en la última mitad del siglo XVIII. Puiblanch la conoce y la maneja para proporcionar argumentos que justifiquen acabar con el Santo Oficio, demostrando ser un buen conocedor de los motivos de tensión entre la jurisdicción eclesiástica e inquisitorial a finales del siglo xvIII. Nunca se puede olvidar que él, al igual que J.A. Llorente, fueron contemporáneos del Santo Oficio, incluso este último un secretario del Consejo de Inquisición ${ }^{18}$. La interpretación política de ambos está un tanto cargada por la realidad del Tribunal en aquellos años y el papel que jugó en tan conflictiva realidad política, a veces no exento de contradicciones. Esto se nota en las referencias a la historia del Tribunal que merecen su atención. Aquí se puede apreciar una visión excesivamente reduccionista en numerosas ocasiones. Quizá sea en el siglo XV\|l donde esta cuestión se observe más claramente. No obstante, partiendo de las categorías morales y políticas de un ilustrado-liberal de la época, Puigblanch construye una de las interpretaciones más lúcidas sobre la dinámica que se estableció entre el Santo Oficio y la Jurisdicción eclesiástica ordinaria.

Llorente parte de unos presupuestos bastantes similares a los que había defendido Puigblanch y que eran patrimonio de los grupos ilustra-

16 Ibidem, pág. 433.

17 Ibidem, pág. 435, nota 1

18 Llonente, J. A., Noticia biográfica (Autobiografía). Madrid 1982. 
dos que habían evolucionado hacia el liberalismo por aquellos años. En cambio, la documentación que utiliza es notablemente más completa, si bien la falta de citas en su obra impide saber exactamente con que papeles trabajó. Llorente realizó un estudio de la cuestión que nos ocupa quizá más analítico y sintético que Puigblanch con el cual, por lo demás, coincide básicamente en sus conclusiones ${ }^{19}$. Su trabajo más sistemático está dedicado a los primeros de años de vida del tribunal ${ }^{20}$. También hay que tener en cuenta que su seguimiento de los conflictos se orienta más a los que se produjeron con los cuerpos burocráticos seculares, que a los eclesiásticos y el tratamiento que hace de ambos es muy desigual en el tiempo y en el espacio. Tampoco cuenta con un análisis preciso de cuáles fueron las bulas papales, cédulas reales, etc., en que se basaron los privilegios de los miembros del Santo Oficio, cómo evolucionaron... No obstante, es imprescindible leerlo con la mayor atención porque, por mucho que le duela a Menéndez Pelayo ${ }^{21}$, Llorente continúa siendo uno de los autores que mejor conoció la documentación inquisitorial y de los más brillantes y atinados en sus valoraciones políticas. Desde luego, su interpretación de los conflictos que originó el ejercicio de los privilegios inquisitoriales sobre sus servidores es uno de los más lúcidos. No en balde él tuvo ocasión de conocer desde dentro y desde una posición excepcional el funcionamiento de la dirección inquisitorial.

Llorente entiende que Fernando el Católico concedió abundantes privilegios a los miembros de la Inquisición, pero ésta desde los primeros momentos realizó un gran esfuerzo por ampliar su poder.

«No bastaron a templar el sistema de ambición de los tribunales del Santo Oficio las leyes generales de Castilla y América, las particulares, bien que heterogéneas, de cada uno de los reinos que componían la corona de Aragón, las reales cédulas declaratorios expedidas por los reyes con frecuencia, ni las cartas acordadas del Consejo mismo de la Inquisición» ${ }^{22}$.

Los tribunales inquisitoriales se saltaron sistemáticamente, tanto las bulas y breves papales, como las leyes de los distintos reinos.

19 LlORENTE, J. A., Historia crítica de la Inquisición en España, cuatro vols. Madrid 1981. La información se encuentra muy dispersa a lo largo de toda la obra y en particular en los tomos II y IV.

20 Llorente, J. A., La Inquisición y los españoles, título bajo el que V. Fernández Vargas ha publicado la Memoria Histórica. Madrid 1967.

${ }_{21}$ Historia de los heterodoxos españoles, T. II. Madrid 1978, pág. 675ss.

22 Llorente, J. A., Historia crítica, op. cit., T. II, pág. 354. 
Llorente, al igual que Puigblanch, tuvieron mucho empeño en destacar el protagonismo de todas las escalas de servidores del Santo Oficio en el origen de estos conflictos, y el amparo que encontraban en los inquisidores, sostenidos, a su vez, por la dirección inquisitorial En estas circunstancias, los inquisidores tenían una irresistible propensión a utilizar las censuras eclesiásticas contra cualquier órgano de justicia o de gobierno, secular o eclesiástico, que se les opusiese. De esta forma se creaba una situación peculiar:

«Las leyes del reino prohibían defender con censuras la jurisdicción temporal, bajo cuya denominación se comprende todo lo que no es espiritual, que recibió su ser en concesiones y tolerancias de los reyes. Pero los inquisidores eludían las leyes aparentando que, aunque la superficie de la disputa parecía ser sobre inteligencia de un privilegio, el fondo era defender la jurisdicción espiritual recibida del papa para castigar herejes, pues aquello sólo era un medio que auxiliaba este fin " ${ }^{23}$.

Incluso los inquisidores llegaron a escribir libros y papeles afirmando que no habían recibido jurisdicción del rey. La Inquisición consiguió su autonomía utilizando el «sistema de buscar protección en la corte cuando les conviene contra Roma, y en esta capital cuando es útil contra la tempestad que amanece por parte del soberano territorial» ${ }^{24}$. Esta dialéctica, que años antes ya había señalado Puigblanch con idéntica precisión ${ }^{25}$, se dio, según Llorente, con singular intensidad en los reinados de Felipe IV y Carlos II ${ }^{26}$.

Es bastante reducida la atención que Llorente dedica a los enfrentamientos de competencia, asistencia a actos públicos, etc., entre la Inquisición y los "obispos». Lo que le preocupa son los conflictos entre los inquisidores y la jurisdicción secular y, al hilo de este relato, realiza alusiones dispersas sobre el otro aspecto, si bien su valoracion global es muy clara:

«humilló y aún prendió a los arzobispos, obispos, deanes, dignidades y canónigos de iglesias metropolitanas, datedrales y colegiatas, curas párrocos y otros clérigos respetables» ${ }^{27}$.

A continuación hace un sucinto resumen de algunos conflictos en los que los inquisidores, apoyados por el Inquisidor General y Consejo, lo-

\footnotetext{
${ }^{23}$ Historia crítica, op. cit., págs. 353-359, la cita textual pág. 357.

Ibidem, pág. 362.

La Inquisición sin máscara, op, cit., pág. 402.

LloRENTE, J. A., La historia crítica, op. cit., T. II, pág. 358.

Ibidem, pág. 356 .
} 
graron imponer su autoridad sobre los «obispos», aunque éstos contasen con el apoyo de los Consejos territoriales donde estaban ubicados sus obispados 0 , incluso, con el del mismo Papa ${ }^{28}$.

El éxito inmediato de la obra de Llorente tendió a anular a Puigblanch. Así el primero dio lugar a una interminable saga de epígonos, generalmente poco inspirados, que se dedicaron a sintetizar pedagógicamente su obra. En realidad, eran liberales españoles, franceses o de cualquier otro punto de Europa, que utilizaban la gran cantidad de datos y valoraciones realizadas por Llorente para demostrar los «horrores» del Antiguo Régimen encarnados en la Inquisición y una Iglesia cada vez más protagonista en el conjunto de fuerzas conservadoras. Era su forma de reivindicar las "virtudes" del liberalismo. Desde entonces la Inquisición se convirtió en el símbolo preferente del Antiguo Régimen. Ninguno de estos propagandistas realizó una valiosa aportación, partiendo de un análisis documental específico. Llorente era la fuente casi exclusiva en la que se alimentaban. Inevitablemente, la interpretación de esta fuente fue modelada a gusto de cada autor y, sobre todo, progresivamente esquematizada con arreglo a las necesidades de la propaganda liberal de cada momento.

\section{LAS CONSECUENCIAS EN LA BIBLIOGRAFIA INQUISITORIAL DE LA REVOLUCIÓN DE 1868 Y PRIMERA REPÚBLICA}

La caída del desacreditado estado moderado y la expulsión de Isabel II en 1868 rompieron el difícil equilibrio entre el estado liberal y la Iglesia, plasmado en el concordato de $1851^{29}$. A partir de este momento, las convulsiones políticas, la Segunda Guerra Carlista, la proclamación de la Primera República o los estallidos sociales, etc., crearon un período de ensayos constitucionales, constantes cambios de gobierno y un vacío de poder cada vez más evidente. El peligro de agitación social en las ciudades y la aparición en escena de un activo movimiento obrero y de la Primera Internacional, junto a la conciencia entre el grueso de la jerarquía eclesiástica de las escasas posibilidades de triunfo de la opción carlista, hicieron que ésta no pasase al enfrentamiento abierto con los sucesivos gobiernos de estos agitados años. Ni por parte de la Iglesia ni de los gobiernos hubo interés en dar lugar a una fractura definitiva, que implicase una ruptura total de relaciones o la creación de una situación política más explosiva.

28 Ibidem, págs. 366, 367, 372.

29 Revuelta González, M., La política religiosa de los liberales en el siglo xix. Madrid 1973. 
A pesar de los deseos de evitar la ruptura las relaciones entre Estado e Iglesia se desarrollaron en un marco de gran tensión con momentos de auténtica crispación. Entre los conflictos abiertos de determinados obispos con los sucesivos gobiernos y las críticas durísimas de los propagandistas católicos, la Iglesia luchó por evitar la libertad de culto, la separación de la Iglesia del Estado o la difusión de doctrinas «impías" ${ }^{30}$. Las relaciones con la Iglesia tuvieron una destacada importancia en la gestión de los gobiernos del período, pero no fue el asunto más acuciante. Se realizaron esfuerzos por crear un nuevo marco de relaciones con la Iglesia, pero estuvieron limitados por la propia inestabilidad gubernamental, las urgencias de la guerra carlista, la guerra en Cuba o las constantes sublevaciones urbanas.

En este encrespado ambiente político, el debate ideológico se hizo muy duro. Significativamente, durante los años más conflictivos, entre 1868 y 1874 no vieron la luz libros importantes sobre el Santo Oficio. Habrá que esperar a la resaca de estos acontecimientos, cuando la Restauración esté dando los primeros pasos, para encontrar de nuevo a la Inquisición convertida en un importante eje de la producción historiográfica. A veces son obras de indudables ambiciones intelectuales gestadas durante un tiempo prudencial. Sin duda, fueron concebidas, y seguramente escritas en parte, durante el período más conflictivo, por ello, no es extraño que algunas se publicasen en los primeros años de la Restauración. Indudablemente, el marco del debate que traslucen estas obras y en el que pretenden incidir ha cambiado notablemente del que vivieron Llorente o Puigblanch. Los partidarios liberales en el seno de la Iglesia, son ahora una pequeña minoría de poco peso específico. El enfrentamiento Iglesia y Estado se plantea abiertamente. Lo que está en juego es el lugar que ha de tener la primera en la estructuración del segundo. Junto a ello, cuestiones que de no menor calado para la estabilidad del Estado como son los «peligros» de la libertad religiosa o libertad de conciencia. En este contexto aparece la vieja justificación de la Inquisición como medio de evitar el peor de los cánceres sociales: la herejía y la desestabilización social y política que entraña. Una cuestión que será radicalmente rechazada por las corrientes más progresistas del liberalismo, que verán en estos planteamientos un esfuerzo por mantener al país dentro

3o Callahan, W. Iglesia, poder y sociedad. op. cit,; LANERo TÁBoAs, A., «La Iglesia española y el poder político (1870-1874). El pensamiento político de la jerarquía española en el sexenio", en Iglesia, sociedad y Estado en España, Francia e Italia (siglo xvill-xX). Alicante 1991, págs. 439-450; Cárcel Ortí, V., La iglesia y la Revolución en España. Pamplona 1979. 
los controles obscurantistas. Los grandes responsables, según ellos, del atraso de España.

\section{Los liberales y su interpretación de la Iglesia y la Inquisición}

A. Millares Torres escribió una historia del tribunal de Canarias en 1874 que, partiendo de postulados críticos, tenía una estructura propia y un acopio de documentación original notable para lo que solía ser común en este tipo de trabajos ${ }^{31}$. En sus tomos se puede encontrar numerosos datos sobre los conflictos de los inquisidores canarios con otros órganos de justicia de las Islas. En su opinión, la Inquisición aprovechó su fuero específico para conseguir una inmunidad mucho mayor de lo que le correspondía. Su influencia en la Corte mediante los confesores de los reyes, que eran hechuras de la dirección inquisitorial, facilitó el que el Santo Oficio saliese triunfante durante los siglos XVI y XVII de sus «abusos» sobre otros órganos de justicia de la Monarquía o la Iglesia ${ }^{32}$. Tras una descripción de diversos conflictos, su conclusión es clara «El título de ministro del Santo Oficio era un salvoconducto, una patente de inmunidad, que se ostentaba con orgullo y se solicitaba con afán» ${ }^{33}$. Habrá que esperar al siglo XVIII para que se ponga de manifiesto una oposición abierta a la Inquisición y a la prepotencia con que se comportaban sus servidores. Para Millares Torres, se trata de una oposición en la que tendrán el mayor protagonismo los sectores ilustrados de las Islas y los miembros de los órganos de justicia y gobierno de la Monarquía ${ }^{34}$.

En Millares ya se puede apreciar una radicalización anticlerical que le conduce a abandonar los análisis que Puigblanch o Llorente habían realizado previamente sobre las relaciones entre el Tribunal y «los obispos». Desde una posición inequívocamente anticlerical, Millares parte del carácter obscurantista y retrógrado del clero regular o secular. Ambos eran auténticos parásitos que ejercían una gran influencia sobre la población para mantenerla en el atraso y la ignorancia ${ }^{35}$. EL Santo Oficio formaba parte destacada de este entramado y se distinguía dentro de él por ser su función específica: perseguir todo atisbo de progreso y libertad. Partiendo de este principio analiza superficialmente la evolución de algún

\footnotetext{
Historia de la Inquisición en las Islas Canarias, cuatro vols. La Laguna 1981, ed. facsímil. Ibidem, T. Ill, págs. 42-43.

Ibidem, págs. 48-49.

Ibidem, T. IV.

${ }^{35}$ Ibidem, T. I., vid. capítulo IV en el que hace un repaso más cargado de tópicos que de información sobre la realidad del clero en las islas.
} 
conflicto entre el tribunal y los "obispos», pero su exposición se centra en la descripción de un caso correspondiente a 1654. Su estudio consiste en la transcripción de una larga carta de los inquisidores al Consejo de Inquisición en la que dan cuenta de los «excesos» del obispo Rodrigo Gutiérrez. A pesar de su limitada base documental y la ausencia de un análisis detenido, su conclusión resulta precisa: «ambas autoridades descendieron al cenagoso terreno de los odios personales, y abusaron del ejercicio de su poder, haciendo pública ostentación de sus ocultas miserias" ${ }^{36}$. Sin duda, ésta es una valoración muy distinta de la que realiza sobre los numerosos conflictos entre los inquisidores y las autoridades seculares de las islas. Mientras en este último tipo de procedimientos señala sin titubeos los abusos del tribunal inquisitorial, cuando se refiere a los choques con los «obispos» todo queda reducido a odios personales y "ocultas miserias" de los representantes de ambas jurisdicciones eclesiásticas igualmente conservadoras y tendentes a la extralimitación y arbitrariedad.

Uno de los epígonos más claros de Llorente fue J. Melgares Marín ${ }^{37}$. Sus páginas resultan bastante ocurrentes a la hora de analizar los aspectos relacionados con el fuero y los abusos inquisitoriales, aunque no tiene más noticias que las proporcionadas por Llorente. Para cuando publica su obra en 1888, ya había desaparecido el interés de los liberales por resaltar los conflictos entre el Santo Oficio y los obispos. Lo único que importa son los que se dan con «las instituciones del Estado». Este autor entiende que, mediante los privilegios del fuero, los inquisidores pretendieron juzgar a sus ministros titulares en asuntos de deudas, tutelas, contratos, tesorerías... Algo que conseguían mediante la utilización de las excomuniones contra los ministros de la justicia secular, que colocaban a éstos en una situación de clara desventaja. Cuando esto no era bastante, los inquisidores se las valían para retrasar la solución de los conflictos de competencias, ocultando entre tanto las pruebas. El resultado era que los miembros de la Inquisición lograban una completa impunidad ${ }^{38}$. La Inquisición nunca diferenció entre los reos por motivo de fe y los de causa civiles y criminales. A todos les caía por igual la infamia de haber estado procesados $o$ condenados en el Tribunal. Una de las peores ignominias

\footnotetext{
36 Ibidem, T, III, vid. capítulo III. La cita corresponde a la pág. 69.

${ }_{37}$ Procedimientos de la Inquisición, persecuciones religiosas, orígenes y carácter eclesiástico, escándalos de los inquisidores, de los frailes y de los papas, terrible lucha de la Inquisición contra el pueblo español, engaños, tretas, misterios, injusticias, crímenes, sacrilegios y aberraciones del clero inquisitorial. La Inquisición y las Cortes de Cádiz, procesos notables y originales, antes inéditos y ahora por primera vez publicados. 2 vols. Madrid 1888.

38 Ibidem, T. 352-353.
} 
en las que podía incurrir cualquier individuo en la época. Valiéndose de estos procedimientos la Inquisición, según Melgares Marín, protegió a todo tipo de rufianes ${ }^{39}$.

A lo largo del siglo XIX la Iglesia fue depurando sus filas de las corrientes ilustradas y liberales para convertirse en el bastión del más firme conservadurismo. De una forma creciente; la ecuación Iglesia-reacción se convirtió en un elemento central de propaganda de las corrientes más progresistas del liberalismo. En consecuencia, quedaron arrinconados los planteamietos que había realizado Puigblanch o Llorente sobre el carácter anticristiano de la Inquisición y la usurpación que hacía de las funciones de los obispos. De este modo, perdió vigor el tratamiento de los conflictos entre los "Obispos" y la Inquisición por conflictos de competencia. Lo único que se mantuvo fue la crítica de las tensiones entre las autoridades seculares y los inquisidores. Para los liberales del siglo XIX semejante simplificación era una manera negativa de presentar las intromisiones en el Estado por parte de la Inquisición en el pasado, que era una forma de criticar la Iglesia «reaccionaria» en su presente. Evidentemente, de ello se deriva un programa para su realidad inmediata de separación Iglesia-Estado.

\section{Jurisdicción eclesiástica, Inquisición y corrientes conservadoras}

La historia de F.J. García Rodrigo ha sido injustamente relegada ${ }^{40}$. Publicada al comienzo de la Restauración, constituye el intento más serio de ofrecer una contestación detallada y puntual a Llorente desde una perspectiva inequívocamente conservadora. Su obra parte de una premisa: El Santo Oficio, o un tribunal similar, resulta imprescindible para controlar las nuevas herejías que están impregnando la sociedad y que son tan peligrosas o más que las de Lutero en su tiempo. Para él las nuevas herejías son el liberalismo, el federalismo y, sobre todo, el socialismo o el anarquismo que por aquellos años estaban cobrando auge en España. Frente a ellas, como en el pasado, sólo cabe la recristianización de la sociedad mediante una intensiva labor pastoral, acompañada por una rigurosa censura y la persecución de los que pretenden subvertir el orden social y destruir la religión. Para conseguir este objetivo hay que fijarse en lo que sucedió con la fundación del Santo Oficio. Fue la colaboración entre los reyes, la Iglesia y el pueblo, la base de un gigantesco impulso

39 Ibidem, pág. 363.

40 Historia verdadera de la Inquisición, tres vols. Madrid 1876-1877. 
antiherético sobre el cual se construyó la grandeza de la Iglesia Católica y del Imperio español. Para García Rodrigo, la Iglesia es la única capaz de conservar la unidad política y social de España. Desde semejantes presupuestos políticos reivindica, para su presente, la renovación de la alianza entre el poder espiritual y temporal. Lo que según él estuvo en el origen de la grandeza de la Monarquía española en los siglos pasados, constituyendo la Inquisición la manifestación más destacada y ejemplificadora de esta conjunción. Es decir, cuando escribe sobre la Inquisición está argumentando un proyecto político «contrarrevolucionario» de colaboración entre la Monarquía y la Iglesia.

Utiliza la documentación inquisitorial para repetir sus argumentos, para defender sus causas y hacerla víctima de sus constantes enemigos. En sus páginas se encuentra frecuentemente el eco de los razonamientos inquisitoriales. Este acriticismo le impide pergeñar elementos más interesantes de un análisis histórico sobre Tribunal y sus circunstancias. Algo francamente lamentable en quien, como García Rodrigo, tenía un conocimiento de la documentación muy superior a lo que era habitual en el siglo pasado. Su marcado tinte conservador no debe empeñar los méritos de la obra. Su acercamiento a las fuentes es sólo comparable al que años antes había ofrecido Puigblanch, e incluso, se acerca al de Llorente, a quien Ilega a superar en el tratamiento de algunas cuestiones concretas. Realiza análisis dignos de consideración, sobre algunos aspectos jurídicos del Tribunal. En cambio, en otros casos, como es su información y valoración de los reos y sus «herejía»..., se limita a recoger la versión de los inquisidores sobre sus víctimas. Sin duda, la vertiente represiva del Tribunal fue la que recogió en el siglo XIX opiniones más sesgadas. García Rodrigo es un polo, Llorente con sus distorsionadas cifras de procesados es el otro.

La obra de García Rodrigo está claramente dirigida a convencer y suministrar argumentos a sectores católicos que no están identificados con el Tribunal o dudan de su justificación histórica. En las primeras líneas de su obra explica claramente sus objetivos:

«Tanto se ha mentido sobre la Inquisición, que las mismas exageraciones hacen patente la calumnia. Ni el cristianismo imparcial puede convencerse de que la Iglesia verdadera, santa e infalible, sancionará con su aprobación una serie no interrumpida de atropellos y bárbaros suplicios».

«Desgraciadamente - continúa García Rodrigo- algunos católicos, como el canónigo J. Llorente, se han convertido en los principales difusores de argumentos y falsedades que hasta entonces sólo habían ex- 
puesto los herejes" ${ }^{41}$. Por ello, tiene un gran interés en resaltar el origen del Santo Oficio. En efecto, para él, como afirma acertadamente, aquél surge por las bulas y breves de la Santa Sede. Para llegar a este punto tiene en cuenta tanto la narración de los sucesos, como las disposiciones papales que están detrás de la creación del Tribunal. Esto, según él, es una consecuencia de la plena facultad de la Iglesia sobre sus propios asuntos encarnada en la jurisdicción soberana del Papa, delegada directamente por Cristo. Por ello, cuando el Papa concedió la jurisdicción sobre la herejía a los inquisidores, cercenando la jurisdicción que antes tenían los obispos en estas cuestiones, adoptó una decisión legítima e históricamente justa. En última instancia, apostilla García Rodrigo, todos los tribunales eclesiásticos han sido creados por la autoridad pontificia y el que censura sus actos «se declara en rebelión contra su legítimo poder y como cismático abandona la comunión católica» ${ }^{42}$. Es decir, los católicos han de permanecer unidos tras la jurisdicción del Papa.

Para García Rodrigo los conflictos por cuestiones de fuero surgieron porque los jueces, ya sean eclesiásticos o seculares, no respetaron los acuerdos o concordias entre la justicia ordinaria y la Inquisición. Es falso que la Inquisición ejerciese un poder arbitrario y tiránico. Todo lo contrario, se defendió contra las agresiones de vicarios y ministros reales desaprensivos influidos por el «nefasto» regalismo en muchos casos. Según él, la Inquisición desde mediados del siglo XVII tenía menos poder del que Llorente y otros autores habían señalado. Desde estos años comienza a sufrir un constante acoso, que se acentuará con la Junta Magna de 1696. Cuando los reyes comenzaron a dejarse "adular" por el regalismo a principios del siglo XVIII ${ }^{43}$, la Inquisición comenzó a declinar y a verse «humillada" por jueces y ministros que perseguían la destrucción de los principios que ella encarnaba. A los conflictos con la jurisdicción eclesiástica ordinaria apenas si dedica atención, porque «León $X$ prohibió bajo pena de excomunión a los tribunales eclesiásticos entender por vía de recurso en causas reservadas al Santo Oficio» ${ }^{44}$. Sólo en determinados conflictos que surgieron entre los inquisidores y los cabildos eclesiásticos, algunos miembros de éstos, consiguieron el apoyo de los ministros reales y gracias a ello lograron inclinar la voluntad del rey en un sentido contrario al Tribunal ${ }^{45}$. De este modo, los conflictos entre la jurisdicción inquisitorial

\footnotetext{
lbidem, T. I. pág. IX.

Ibidem, T. I. pág. 256.

Ibidem, T. III, págs. 332-359.

Ibidem, T. Il. pág. 107

Ibidem, T. III, págs. 337-338.
} 
y la ordinaria eclesiástica, quedan reducidos a maniobras de algunos canónigos apoyados por unos ministros de la Monarquía fáciles de convencer para prolongar su poder sobre los asuntos espirituales.

Millares al igual que Melgares Marín o García Rodrigo son un buen exponente de una importante inflexión que se estaba dando por aquellos años y que afectará al grueso de cuantos escriben sobre el Santo Oficio, ya sea desde posiciones liberales o conservadoras: la equiparación entre Iglesia e Inquisición. Una curiosa coincidencia. Los defensores de ambas posiciones llegaban a un punto similar a la hora de valorar las relaciones entre la Inquisición y la Iglesia. Partiendo de una distinta valoración política sobre los grandes conflictos que se estaban dando por aquellos años entre el naciente estado liberal y la Iglesia, llegaban a una conclusión muy similar en su caracterización sobre las relaciones entre la jurisdicción eclesiástica ordinaria y la inquisitorial. No obstante, éstas no fueron las únicas interpretaciones políticas que si hicieron por estos años. Hubo otras que a largo plazo tuvieron un influjo mayor.

Menéndez Pelayo realizó un inteligente análisis de las controversias jurisdiccionales. A diferencia de García Rodrigo, Menéndez Pelayo nunca estuvo muy informado sobre la Inquisición, pero si defendió una interpretación política muy efectiva, destinada a ser la más influyente en el siglo xx. No entraba en el debate sobre la bondad o maldad de lo que hacían los jueces inquisitoriales en los pleitos civiles o criminales. No lo consideraba necesaric. Acorde con este planteamiento, apenas si dedica dos páginas a esta cuestión en su abultada obra y, por supuesto, ninguna referencia valiosa sobre conflictos de competencia entre inquisidores y obispos. En su opinión estas disputas «fueron un semillero de pleitos», pero «se decía y disputaba libremente entre buenos y fervorosos católicos y por entonces no era ocasión de peligro alguno " ${ }^{46}$. Es decir, no tuvieron apenas importancia. Para Menéndez Pelayo el Santo Oficio no tuvo una dimensión política por sí mismo. A lo largo de su historia estuvo notablemente ligado a la Corona y dedicado específicamente a cuestiones de fe.

Al negar la importacia de los sonflictos de competencia, Menéndez Pelayo, de un plumazo y de forma muy inteligente, anuló el eje central de lo que hasta entonces había sido el asidero fundamental de las críticas liberales sobre los excesos del Santo Oficio. Si eran irrelevantes las protestas de las autoridades civiles y eclesiásticas contra lo que hacían los inquisidores para entender la imbricación de la Inquisición con la socie-

46 Historia de los heterodoxos españoles. Madrid 1978, vol. Il, pág. 352. 
dad, quedaba reducido al mínimo el papel político del Tribunal y la expresión de la oposición del conjunto de los reinos a él por medio de memoriales... Con esta interpretación desaparecía un aspecto central del trabajo inquisitorial: su papel en la reproducción de la sociedad estamental. En su opinión, la evolución del Santo Oficio dependió en todo momento de los reyes. Cuando éstos le favorecieron tuvo energía y capacidad para cumplir con éxito su misión. Cuando no, como es el caso de los Borbones, declinó irremisiblemente. Esta visión es la que ha prevalecido en este siglo y la que más ha contribuido a enterrar las sugerencias que años antes habían realizado Puigblanch o Llorente. En ella la historia del Santo Oficio perdía la independencia y la autonomía que le proporciona la específica jurisdicción delegada directamente en el Inquisidor General por el papado, respecto a la Monarquía y a la misma Santa Sede. De esta forma el Tribunal quedaba reducido a un puro instrumento del absolutismo real.

\section{INQUISICIÓN Y JURISDICCIÓN ECLESIÁSTICA EN LEA}

Ch. Lea concedió una gran importancia a los aspectos derivados del fuero. Sin duda, es el autor que más los ha valorado y que mejor ha situado la trascendencia de los conflictos de jurisdicción en la evolución del Tribunal. La documentación que utiliza es de primera mano, abundante y bastante contrastada. Es decir, de primera calidad. Su perspectiva se centró más en destacar los abusos que se produjeron por la mala utilización de los privilegios inquisitoriales sobre sus servidores, mediante la descripción de un gran número de casos concretos, que en los fundamentos jurídicos que lo permitieron y los intereses que hubo detrás de tanta conflictividad ${ }^{47}$. A fin de cuentas, eran abusos de individuos permitidos por la constante protección de la dirección inquisitorial. La ilimitada jurisdicción del Santo Oficio sobre los delitos contra la fe y las equiparables garantías judiciales para quien se encuadraba en sus filas, ardientemente defendidas por los inquisidores, proporcionaron a su organización unos privilegios muy superiores a los del resto de los ministros del rey. Para Lea «todos los implicados en el Santo Oficio y sus actividades estaban envueltos en una inviolabilidad no concedida a ningún otro sector de la comunidad» ${ }^{48}$. Naturalmente, esta inviolabilidad se tra-

47 Historia de la Inquisición española. Madrid 1983, vol. I, en especial la segunda parte: Relaciones con el Estado.

4 LEA, Ch., Historia de la Inquisición española, T. I. Madrid 1983, pág. 416. 
dujo en que sus miembros eran juzgados por los inquisidores, recibiendo penas muy inferiores a las que hubiesen correspondido de haberlo sido por la justicia ordinaria. La Inquisición se convirtió en una organización autónoma en «un imperio in imperio» ${ }^{49}$, al margen de toda sujeción a las leyes de los reinos. La Corona realizó notables esfuerzos por reducir el margen de discrecionalidad de los jueces inquisitoriales en sus acciones derivadas de la defensa del fuero, pero no alcanzó grandes logros durante los siglos XVI y XVII.

En el terreno de la conflictividad entre Inquisición y «obispos» el análisis de Lea destaca también por un rigor y globalidad lejos de ser superado. En esta cuestión, como en tantas otras, su obra es de imprescindible consulta. Es el primero que realiza un estudio en términos básicamente correctos, teniendo en cuenta los ejes fundamentales de lo que fue la polémica sobre los privilegios que alegaron los inquisidores sobre sus servidores eclesiásticos frente a los obispos.

«Los ordinarios episcopales, provisores y vicarios generales sostenían que, excepto en casos de fe, tenían jurisdicción exclusiva sobre todos los clérigos; que la jurisdicción temporal de la Inquisición era una concesión real que no podía reemplazar al Derecho Canónico» ${ }^{50}$.

Análisis que fue radicalmente negado por el Santo Oficio. Éste, según Lea, contaba en estos enfrentamientos con la ventaja añadida de obligar a los «obispos» a defenderse sin contar con el apoyo de su Consejo territorial respectivo, ya que «los Consejos admitían que no podían tener parte en disputas eclesiásticas»" ${ }^{51}$. Así, aunque las concordias firmadas entre Inquisición y jurisdicción real recomendaban que los inquisidores no lanzasen a los tribunales eclesiásticos inhibiciones generales para impedirles proceder contra familiares, comisarios..., de hecho, los tribunales eclesiásticos se encontraban sin protección, al arbitrio de los inquisidores. Un análisis de algunos conflictos de competencia vienen a demostrar esta aseveración en distintos territorios de la Monarquía. En Mallorca, en cambio, tras una larga batalla, los canónigos consiguieron un breve de Su Santidad para evitar ser procesados por los inquisidores, cuestiones distintas a las de herejía ${ }^{52}$. En conjunto, no obstante, Lea juzga con dureza la actuación de los «obispos» frente a la Inquisición acusándoles sin paliativos de consentir sus excesos ${ }^{53}$.

49 lbidem, pág. 303.

$50 \quad$ lbidem, T. I, pág. 548.

lbidem, pág. 549

52 Ibidem, págs. 551-560

53 Ibidem, pág. 618. 
En conjunto, Lea valora de esta forma los conflictos entre el Santo Oficio y los ordinarios:

«la Inquisición era un todo organizado con métodos violentos y expeditivos para imponer sus pretensiones y protegerlas perfectamente de toda clase de ataques, mientras que el episcopado era un cuerpo disperso y de difícil manejo, cuyos miembros actuaban por separado, impotente en conjunto para defender a los representantes a través de los cuales actuaba frente a quienes sostenían que todo lo relativo a sí mismos era una materia de fe, de la cual ellos tenían conocimiento exclusivo» ${ }^{54}$.

En su estudio Lea parte de una comprensión bastante correcta, aunque incompleta, de la naturaleza de los problemas que enfrentaron a ambas jurisdicciones. Sin embargo, presenta más deficiencias a la hora de comprender la dialéctica política que implicaban este tipo de conflictos y su importancia, no sólo para el reino, sino también para la concurrencia de poderes en el seno de la propia Iglesia, o la importancia que tuvo la actuación del papado y sus representantes.

Toribio Medina, contemporáneo de Lea, en sus valiosos trabajos sobre los tribunales de la Inquisición en América, dedicó una considerable atención a los conflictos jurisdiccionales de la Inquisición con otros órganos de justicia y gobierno. El tratamiento que realiza es bastante descriptivo ${ }^{55}$, acudiendo con frecuencia a la transcripción de documentos a través de los cuales se aprecian los «abusos» de los tribunales del Santo Oficio y sus ministros. A través de algunas de estas descripciones se pueden seguir algunos de los motivos más frecuentes de conflicto entre ambas jurisdicciones: los intentos por parte de los inquisidores de proteger a comisarios y otros ministros eclesiásticos del castigo por parte de la jurisdicción eclesiástica ordinaria ${ }^{56}$.

\section{E. HACIA LA ANULACIÓN DEL PROBLEMA EN EL SIGLOXX}

La bibliografía posterior a Lea ha tendido a pasar por alto los motivos por los que surgen los conflictos en el mantenimiento de las exenciones judiciales o fiscales de los servidores inquisitoriales, apartando esta cuestión del lugar central que le corresponde. En el mejor de los casos, se

54 lbidem, pág. 406.

55 Historia del tribunal del Santo Oficio de la Inquisición en México. México 1987, Ed. facsímil, págs. 151-172.

56 Ibidem, pág. 73ss. 
han descrito algunos excesos y corruptelas de los miembros de la Inquisición y cómo se valían de su fuero privativo, pero no se ha sabido entender su importancia para entender la inserción del Santo Oficio en la sociedad estamental y sus relaciones con el resto de los cuerpos burocráticos. Sin duda, ésta ha sido una valoración muy distinta a la que realizaron los autores del siglo pasado.

En este siglo no ha avanzado el análisis sobre estas cuestiones y la trascendencia política del Tribunal. Antes al contrario, ha abandonado algunas de las cuestiones, como lo referente al fuero, que hasta entonces habían sido un motivo destacado del trabajo historiográfico. La corriente que tradicionalmente había cambiado este tipo de cuestiones, los liberales, habían cambiado significativamente sus perspectivas. $Y$ es que las circunstancias habían cambiado radicalmente. En los primeros decenios de este siglo el auge del movimiento obrero, del sindicalismo de la CNT o de la UGT, del PSOE, la conflictividad social, etc., hacía que la vieja polémica sobre la Inquisición hubiese perdido su interés. No lo tenía para las corrientes intelectuales más avanzadas que aspiraban a un cambio revolucionario de la sociedad y del poder político, pero también lo había perdido para los republicanos que deseaban cambios importantes en el sistema político a todos los niveles, incluida la relación entre el Estado y la Iglesia.

Las corrientes predominantes en este siglo, la autodenominada "católica» o el positivismo semita, no han prestado atención a los asuntos derivados de los conflictos de los servidores inquisitoriales. En realidad, ambas han coincidido bastante en sus caracterizaciones políticas sobre el Santo Oficio. Los «católicos" como Bernardino Llorca, Pinta Llorente, etc., que han sido quienes más intensamente se han volcado en el estudio de la Inquisición, han contribuido notablemente a vaciarla de cualquier contenido político, orientándose sólo a la investigación de los procesados por sus tribunales ${ }^{57}$. En su planteamiento, al igual que en Menéndez Pelayo, por el cual están muy influidos, subyace la negación del carácter político de la Inquisición. Ésta habría sido una organización centrada en la represión de la heterodoxia y la herejía. Gracias a su labor se evitaron las guerras civiles o de religión en la Península durante los siglos de la modernidad. En este sentido, durante los siglos XVI y XVII hubo una armónica colaboración entre la Inquisición y el Estado, porque cada uno

57 Sobre la evolución de estas corrientes vid. AVILÉS, M., "La literatura Inquisitorial (Aportaciones a la historia de un género historiográfico)», op. cit., pág. 87. LÓPEZ VELA, R., «Inquisición y Estado. Los fundamentos historiográficos de una interpretación política", Chronica Nova $n^{\circ} 18$ (1990), págs. 267-342. 
de ellos aceptaba y sostenía el papel del otro. El santo Oficio mantenía la paz religiosa y social con su defensa a ultranza de la pureza del cristianismo, que era el basamento social y político del Estado. Éste, a su vez, sostenía con el poder temporal a la Inquisición en todos los terrenos y la defendía de sus enemigos, valorando en toda su dimensión su importancia para el gobierno del reino y el bienestar de los súbditos. Una compenetración ideal, que hace pensar en el papel que a sí misma se asignaba la Iglesia en su participación política durante aquellos años y que tanta influencia alcanzará después de la Guerra Civil. La Iglesia es un poder espiritual, subordinado al Estado en las cuestiones temporales, pero éste también está subordinado a la Iglesia en lo espiritual, intelectual, etc. Una pléyade de intelectuales eclesiásticos, entre los cuales destacó B. Llorca, se encargó de desarrollar estas ideas y de reinterpretar el pasado con arreglo a ellas. $Y$, como no, la revisión de la historia inquisitorial ocupó un papel importante.

En los últimos años se observa una tendencia incipiente a recuperar esta dimensión en el sentido que ya había diseñado Lea ${ }^{58}$. Pero por ahora, no son más que pequeños trabajos monográficos con interesantes sugerencias. Son, por un lado, estudios que ponen de manifiesto la reducción de la jurisdicción episcopal que significaba la creación de la Inquisición y como esto fue una permanente fuente de tensiones entre ambas jurisdicciones ${ }^{59}$. Otros trabajos, como el de Colom i Palmer, han planteado las tensiones entre la jurisdicción inquisitorial y la ordinaria en términos de conflictos de competencias en un marco territorial y cronológico determinado, analizando sus implicaciones ${ }^{60}$. Su aportación tiene singular relevancia por cuanto en Mallorca se dieron algunos de los más importantes conflictos entre el tribunal del Santo Oficio y el cabildo eclesiástico. Efectivamente, a través de su análisis se pueden seguir los intentos del tribunal isleño para imponer su autoridad sobre el cabildo eclesiástico en cuestiones ajenas a la fe.

58 Castañeda delgado, P., y Hernández aparicio, P., La Inquisición de Lima (1570-1635). Madrid 1989, págs. 101-199; COLOM I PALMER, M., "Los breves de Urbano Vill y la conflictiva exención de los eclesiásticos mallorquines de la jurisdicción inquisitorial», en Perfiles jurídicos de la Inquisición española, op. cit. Madrid 1989, págs. 449-460.

59 ALCALÁ, A., «Herejía y Jerarquía. La polémica sobre el Tribunal de Inquisición como desacato y usurpación de la jurisdicción episcopal», en Perfiles jurídicos de la Inquisición española, op. cit., págs. 61-87.

60 «Los breves de Urbano VIII y la conflictiva exención de los eclesiásticos mallorquines de la jurisdicción inquisitorialm, en $/$ bidem, págs. 449-460. También merece especial consideración el trabajo de DE Miguel, M. L., Ibidem, «El problema de los conflictos juridiccionales (memorial de Antonio Trejo a Felipe IV)", en Inquisición española. Nueva visión; nuevos horizontes, (Ed.) Pérez Villanueva, J., Madrid 1980, págs. 83-88. En él se analiza el importante conflicto de jurisdicción entre el obispo Trejo y el tribunal de la Inquisición de Murcia. 
Una mención especial merece el tratamiento que de esta cuestión ha realizado la historiografía italiana. Su estudio se ha centrado preferentemente en la relación que se estableció entre las inquisiciones dependientes de la Congregación del Santo Oficio romano, o los tribunales inquisitoriales de Sicilia y Cerdeña dependientes de la Inquisición española, respecto a la jurisdicción ordinaria en Italia. El contraste que aparece resulta muy interesante. En efecto, el planteamiento que ha realizado $A$. Borromeo sobre la relaciones entre la jurisdicción inquisitorial y eclesiástica en los dominios italianos de la Monarquía Católica, demuestra hasta qué punto las relaciones entre ambas jurisdicciones fueron distintas en función de sus diferentes facultades y modelos organizativos ${ }^{61}$. Su análisis recoge otra tradición bastante alejada de la que se había fraguado a través del estudio de la Inquisición española. En él se puede comprobar hasta qué punto ésta fue el fruto de unas facultades y un modelo organizativo específico, uno de cuyos puntos esenciales fue precisamente la relativa autonomía que consiguió respecto a los jueces ordinarios de la jurisdicción episcopal. Una cosa que, sin embargo, no sucedió con tanta intensidad en otros puntos de la Italia española durante el quinientos o el seiscientos. En buena medida, la constatación de estas diferencias animó a los eclesiásticos de Cerdeña y Sicilia a enfrentarse a sus respectivos tribunales inquisitoriales dependientes del Inquisidor General y Consejo. Significativamente, los motivos de tensión entre ambas jurisdicciones no sólo surgieron por cuestiones de fuero, sino también por el conocimiento de algunos delitos ${ }^{62}$.

\section{CONCLUSIÓN}

Un balance de lo que se ha escrito en lo relativo al fuero y el privilegio inquisitorial hace que resplandezca con brillo lo que se hizo en el siglo pasado o a principios del Xx. Como en cualquier otro campo que se plantee una valoración política del Santo Oficio, la historiografía del presente siglo ha proporcionado aportaciones escasas, salvo algunas excepciones. Generalmente, sus valoraciones han partido de un estatalismo que ha

\footnotetext{
61 «Contributio allo studio dell'Inquisizione e dei suoi rapporti con il potere episcopale nell' Italia Spagnola del cinquecento», Annuario dell'stituto Storico Italiano per l'età moderna e contemporanea, vol XXIX-XXX (1977-1978), págs. 219-276. Es interesante también el planteamiento que hace A. Prosperi, vid. «Per la storia dell'Inquisizione Romana", L'Inquisizione Romana in Italia nell'età moderna. Archivi, problemi di metodo e nuove ricerche. Roma 1991, pag. 60 ss.

62 BOER, W de, «Ad audendi non videndi commoditatem. Note sull'introduzione del confessionale sopratutto in Italia», Quaderni Storici, n 77 (1991), págs. 543-572.
} 
impedido entender el papel político de la Inquisición, tanto en sus conflictos jurisdiccionales como en sus relaciones con la Monarquía o la Santa Sede. En este sentido, lo escrito por Puigblanch, Llorente o Lea sigue siendo un punto de partida imprescindible. Todos ellos parten de una constatación fundamental: la jurisdicción inquisitorial y la ordinaria eclesiástica no sólo eran distintas, sino que tuvieron abundantes enfrentamientos durante el período. Con matices los tres autores coinciden en señalar la autonomía política de la Inquisición y las posibilidades que ésta brindaba para defender los "excesos» de sus ministros. Éstos son contemplados como una sucesión de desmanes e inmoralidades posibilitados por una jurisdicción muy poderosa, ante los cuales la dirección inquisitorial no actuó imponiendo una disciplina basada en la justicia. Falta, sin embargo, un análisis preciso sobre los privilegios que configuró el fuero inquisitorial, la importancia de las aportaciones de la Santa Sede o de la Monarquía, la forma en que se utilizaron, los intereses sociales que se movieron en torno al fuero inquisitorial, la actitud política de la Inquisición frente a la Iglesia, etc. 